\title{
Beeinflussung der Digitoxinwirkung auf das ausgeschnittene Froschherz durch ultraakustische Schallwellen.
}

\author{
Von \\ Minoru Terui. \\ (照 井 暂) \\ (Aus der Medizinischen Klinik von Prof. Dr. T. Kato, \\ Tohoku Reichsuniversität zu Sendai.)
}

In den letzten Jahren sind die Arbeiten über biologische Wirkungen der ultraakustischen Schallwellen angehäuft publiziert worden. Kusano ${ }^{1)}$ liess auf 500,000 bzw. 1000,000 fache Verdünnungen von Adrenalin ultraakustische Schallwellen (2000 Volt im primären Kreis und eine Frequenz von $46 \times 10^{5} \mathrm{~Hz}$ pro sec) $130 \mathrm{sec}$ lang einwirken und konnte nachweisen, dass die vasokonstriktorische Wirkung des Pharmacums auffallend herabgesetzt war. Ogata und seine Mitarbeiter $^{2)}$ haben auch diesbezügliche Beobachtungen in verschiedenen Richtungen angestellt, indem sie auf die Adrenalinlösungen ultraakustische Schallwellen (1250 Volt im primären Kreis und eine Frequenz von $46 \times 10^{5} \mathrm{~Hz}$ pro sec) einwirken liessen; dabei zeigte sich, dass die blutdrucksteigernde Wirkung des Mittels bei Kaninchen durch $3 \mathrm{~min}$ langes Einwirkenlassen von ultraakustischen Schallwellen abgeschwächt wurde, und dass bei 5-15 min langem Einwirkenlassen dieselbe Wirkung in immer stärkerem Masse verringert war. Des weiteren soll auch die blutzuckersteigernde Wirkung des Adrenalins bei Kaninchen beim 5-15 min langem Einwirkenlassen der ultraakustischen Schallwellen merklich herabgemindert sein.

In der vorliegenden Arbeit wurde der Einfluss der ultraakustischen Schallwellen auf die Digitoxinwirkung studiert. Die Vorrichtung zur Sendung von ultraakustischen Schallwellen wurde dieselbe herangezogen, welche früher von $\mathrm{Ku}$ s a n $\mathrm{o}^{1)}$ verwendet wurde. Die Intensität

1) Ku san o, Tohoku Journ. Exp. Med., 1936, 30, 170.

2) Ogata, Yoshida, Kamibayashi u. Hira o, Osaka Igakkai Zasshi, 1939, 38, 149. 
der Digitoxinwirkung wurde nach der Zeitauder, in welcher das Straub-Yagische Froschherz zum Stillstand kam, beurteilt. Das Herz wurde aus männlichen 20-25 g schweren Rana nigromaculata herausgeschnitten und mit $1 \mathrm{ccm}$ Ringer-Lösung ernährt. Diese Nährflüssigkeit wurde mit $0,1 \mathrm{ccm} 0,005 \%$ iger Digitoxınlösung versetzt, auf welche man ultraakustische Schallwellen $90 \mathrm{sec}$ lang hatte einwirken lassen. Dabei wurde die Temperatur der Digitoxinlösung von $18^{\circ} \mathrm{C}$ auf $26^{\circ} \mathrm{C}$ gesteigert. Mit Rücksicht darauf wurde die Digitoxinlösung von gleicher Konzentration ebenfalls auch auf dem Wasserbad von $18^{\circ} \mathrm{C}$ auf $26^{\circ} \mathrm{C}, 90 \mathrm{sec}$ lang konstant erwärmt und als Kontrolle benutzt. Weiterhin wurde die Digitoxinlösung von $18^{\circ} \mathrm{C}$ Wärme zum Vergleich benutzt. Die Zimmertemperatur wurde bei $20^{\circ} \mathrm{C}$ gehalten. Die Zeitdauer bis zum Eintritt des Stillstandes in einzelnen Fällen sind in beistehender Tabelle zusammengestellt.

\begin{tabular}{|c|c|c|c|}
\hline & Versuch & $\begin{array}{r}\text { Zeitdaue } \\
\text { Stil }\end{array}$ & $\begin{array}{l}\text { bis zum } \\
\text { tand }\end{array}$ \\
\hline \multirow[t]{2}{*}{$\begin{array}{l}\text { Digitoxinlösung } \\
\qquad\left(18^{\circ} \mathrm{C}\right)\end{array}$} & $\begin{array}{l}1 \\
2 \\
3 \\
4 \\
5\end{array}$ & $\begin{array}{l}19^{\prime} \\
17^{\prime} \\
20^{\prime} \\
19^{\prime} \\
19^{\prime}\end{array}$ & $\begin{array}{l}12^{\prime \prime} \\
24^{\prime \prime} \\
12^{\prime \prime} \\
12^{\prime \prime} \\
36^{\prime \prime}\end{array}$ \\
\hline & Durchschnitt & $19^{\prime}$ & $7^{\prime \prime}$ \\
\hline \multirow[t]{2}{*}{$\begin{array}{c}\text { Digitoxinlösung unter } \\
\text { der ultraakustischen } \\
\text { Sehallwellen }\left(26^{\circ} \mathrm{C}\right)\end{array}$} & $\begin{array}{l}1 \\
2 \\
3 \\
4 \\
5\end{array}$ & $\begin{array}{l}27^{\prime} \\
29^{\prime} \\
25^{\prime} \\
24^{\prime} \\
25^{\prime}\end{array}$ & $\begin{array}{l}12^{\prime \prime} \\
12^{\prime \prime} \\
48^{\prime \prime} \\
48^{\prime \prime}\end{array}$ \\
\hline & Durchschnitt & $26^{\prime}$ & $24^{\prime \prime}$ \\
\hline \multirow[t]{2}{*}{$\begin{array}{l}\text { Digitoxinlösung im } \\
\text { Wasserbad }\left(26^{\circ} \mathrm{C}\right)\end{array}$} & $\begin{array}{l}1 \\
2 \\
3 \\
4 \\
5\end{array}$ & $\begin{array}{l}20^{\prime} \\
19^{\prime} \\
21^{\prime} \\
20^{\prime} \\
20^{\prime}\end{array}$ & $\begin{array}{l}36^{\prime \prime} \\
12^{\prime \prime} \\
24^{\prime \prime} \\
48^{\prime \prime}\end{array}$ \\
\hline & Durchschnitt & $20^{\prime}$ & $24^{\prime \prime}$ \\
\hline
\end{tabular}

Aus dem obigen Ergebnisse kann folgender Schluss gezogen werden :

Die Digitoxinwirkung auf das herausgeschnittene Froschherz wird durch ultraakustische Schallwellen abgeschwächt.

Diese Erscheinung dürfte meines Erachtens nicht auf die Steigerung der Wärme, sondern auf eine spezifische Wirkung der ultraakustischen Schallwellen zurückzuführen sein. 